\title{
Research on the Current Situations of the Community Home-stay Pension Services in Beijing
}

\author{
$\mathrm{Na} \mathrm{Yu}$ \\ School of Management and Economics, Beijing Institute of Technology, \\ Beijing, China \\ e-mail: yuna@bjmu.edu.cn
}

\begin{abstract}
Public home-stay pension services have been carried out in Beijing since Year 2010. In this article, the problems of the community home pension service were raised through the analysis of the survey data and researches on the status quo. Meanwhile, suggestions were given on the focus of the work in the future.
\end{abstract}

Keywords- home-stay pension; pension service; life care

\section{INTRODUCTION}

At the end of 2008, Beijing Municipal Government drew up a new pension model called 9064. By 2020, 90\% of the elderly will have home-stay pension services with assistance by social services; $6 \%$ of the elderly will have pension services through community service purchased by the government; the balance of $4 \%$ will be put up in the elderly care service agencies. In order to make sure $90 \%$ of the elderly enjoy care service at home, the Civil Affairs Bureau in Beijing together with another 13 government departments jointly issued the Approach for Beijing Citizen Home-stay Pension Service (including Help to the Handicapped), effective from 1st of January, 2010.

Three years passed since then. How the Beijing community home-stay pension services are carried out? What is the current status and what are the needs of the elderly? In this paper, we will analyze the needs, situations and existing problems of the community home-stay pension services through the survey data, and try to show and analyze the clear picture of the community home-stay pension service in Beijing..

\section{METHOD}

Research objects

This research distributed 986 questionnaires to the elderly who are 60 years old and above, and collected 986 valid questionnaires. Among the 986 elderly, 36\% (355) are male and the balance is female. The interviewees are from 60 -years-old to 94-years-old. Most are from 60-year-old to 80 -year-old, and the interviewees above 80 are minimal. $34 \%$ of the interviewees are senior high school graduates; $28 \%$ has junior high school education, $15 \%$ has primary or lower education, very few have master degrees or above; $22 \%$ graduated from university or specialists. The main source of income of the $96.5 \%$ is their own retirement salary, $1.2 \%$ receive alimony, $3 \%$ have savings and investment income, few receive government grants or other sources of income. Approximately $36 \%$ of the surveyed said their monthly income was between 1,000 to 2,000 yuan, nearly $50 \%$ is between $2000-4000$ yuan, few are lower than 1000 yuan or higher than 4000 yuan.

Research Methods

The questionnaire contains: basic personal information, pension will and pension services, financial security in the status quo, life care status and demands, health care status and demands, solace and legal protection status and demands, volunteer service.

\section{RESUlTS}

1. Analysis of Pension service willingness

$67 \%$ of the elderly prefer staying at home with their family; $18 \%$ are willing to stay with the pension service agencies, to avoid being a burden to the family; the remaining $15 \%$ are willing to try a new of community homestay pension service. This reflects the Chinese people deeprooted concept of staying at home.

2. Analysis of Demands of pension services

(I). Demands on Material Security

Most of the surveyed elderly live with their spouses and/or children. And most of them receive allowance from their Children from now and then, although they mainly rely on their own retirement pay. In the answers about financial conditions, over $50 \%$ of the elderly reckon that their financial conditions are more or less sound; approximately $23 \%$ of them have some difficulties; $19 \%$ consider their own life well-off; only a few respondents consider themselves very poor or very rich. 75 respondents receive the subsidies for the very senior citizens, 5 respondents receive the subsidy for the handicapped, 8 respondents receive the subsidies for the very low-income families, 30 respondents get food vouchers and 4 respondents enjoy some other subsidies, while most of the respondents do not benefit from any kinds of government subsidies.

What troubles the elderly most? 33\% of the respondents agree that their life is very comfortable; while among the troubled elderly, $30 \%$ is because of their low income and over $50 \%$ encountered medical treatment issues. For them, daily chores or loneliness are not main difficulties (ref to Chart.1). Besides of the above problems, poor quality of marriage, housing and the ID registration etc also trouble some of them. This shows that our community home-stay pension service should pay more attention to improve the living conditions of the elderly with low income, and concern on the difficulties and expenses in medical treatment.

About 33\% of the respondents indicate their communities did not provide any services, and $66 \%$ indicate the 
community provides certain services, mostly like medical care, solace and life care.

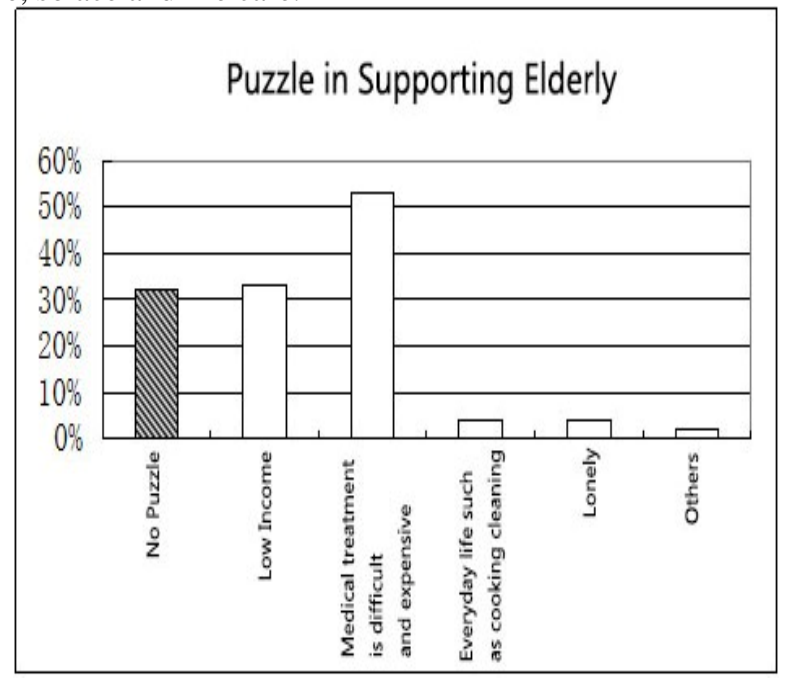

Chart 1 Puzzles of the surveyed in community home pension

(II). Demands on Life Care

Over $90 \%$ of the respondents are able to take care of themselves completely, only $5 \%$ can take care of themselves partly, and about $1 \%$ of them are completely dependent. Out of the 14 selections, most of the Elderly can eat, walk, dress and take medicines independently. Noticeably, more respondents cannot do the housework, cook, go shopping and washing independently. These may be more needed by the advanced-age and the sick elderly.

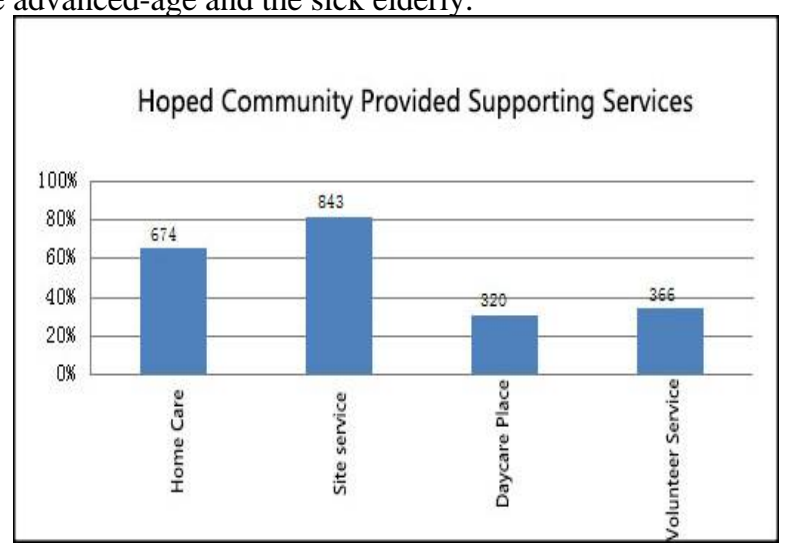

Chart 2 Hoped Life care services of communities

More than $80 \%$ of the respondents want the community to open restaurant and laundries for the elderly. $65 \%$ of the respondents want hourly home care services (ref to Chart 2). These 2 demands are significantly more than the other 2 of day-care centers and volunteers. Over $70 \%$ of the respondents need 1-2 hours of service at home, which is troublesome and labor demanding for them. And they hope the hourly service price could be as low as possible. Nearly $90 \%$ of respondents said they can take care of themselves; $19 \%$ are taken care of by their spouses; $13.5 \%$ by their children; another $3 \%$ by the domestic helper; almost no one by hourly workers, neighbors or community service staff. About 80 per cent of respondents do not know much about the life care services provided by the community or some communities do not provide any life care services. We are somehow surprised by the low coverage of the community life care service. In addition, the services of maintenance, house cleaning and food delivery are more known compared to assistance in taking medicine, going to the toilet and paying bills As not many people receive or even know the community life care service, less than $40 \%$ of the respondents are satisfied, instead most of the respondents are not happy with the service, which tells us that there is still big room for the community service to improve.

(3). Demands on life security

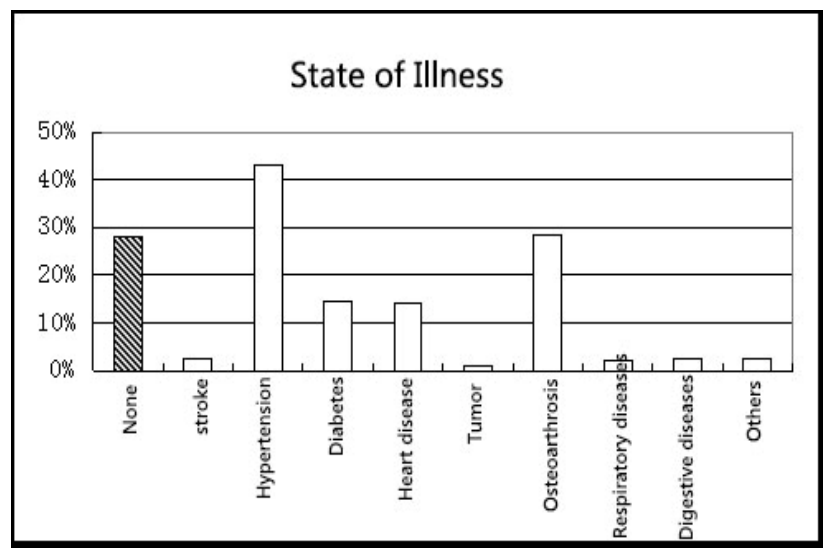

Chart 3 State of Illness of the surveyed

More than 25\% of the respondents do not have any chronic diseases. And the most common diseases are hypertension, osteoarthritis, diabetes and heart disease (ref to Chart 3). Due to the features of long duration, slow recovery and non-obvious symptoms of these diseases, the sick elderly require long-term and sustainable health services. Over $60 \%$ of the respondents are expecting the Community health station could provide regular medical checkup. And the elderly also likes to-door diagnosis and nursing (ref to Chart 4)

More than three-quarters of the respondents pay less than 500 yuan of medical expenses. Over $30 \%$ of the respondents mention that it is difficult to bear such amount of medical expenses. For medical insurance, 66 percent of respondents have the basic medical insurance for urban residents; 26\% enjoyed free medical service; and some of the Elderly whose ID registered in the rural area has the new rural cooperative medical insurance. For the most visited medical organizations, more than $60 \%$ of the respondents choose public hospitals, mainly due to the better service quality and close distance; $16 \%$ frequently go to doctor in the community health stations, because health stations are normally in the community and the drug there is cheaper. Less than $30 \%$ go to the community health stations often or occasionally. Poor service quality and few service contents are the main reasons of not visiting the community health station by the remaining respondents. 


\section{Hoped Services Provided By Community Health Station}

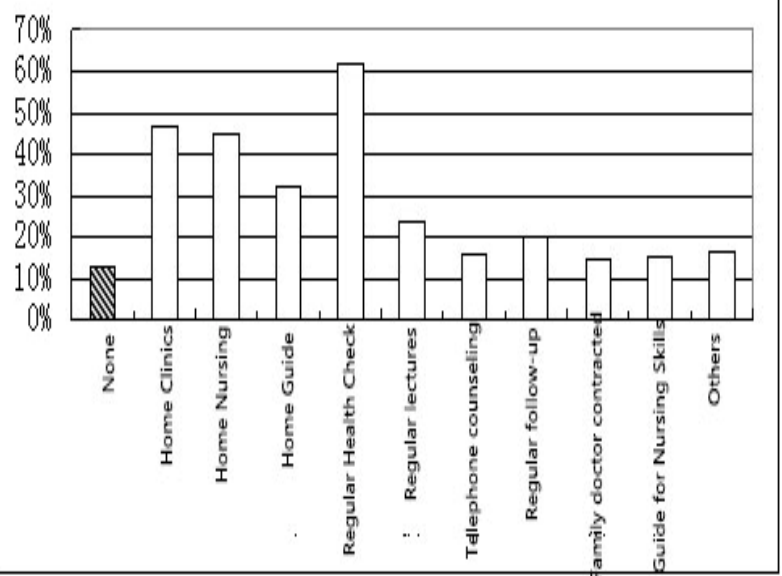

Chart 4 Hoped services provided by community health station (IV). Demands on Solace

$15 \%$ of the respondents are very happy with their life and $24 \%$ of them are happy; $60 \%$ feel it is just so-so; $1 \%$ are not satisfied at all. About $80 \%$ of the respondents never feel lonely; $15 \%$ feel lonely occasionally; nearly $4 \%$ feel lonely often. Nearly $20 \%$ of the respondents hope the volunteer can have a chat or walk with them or do some exercise with them. More than $90 \%$ of the respondents have excellent or good relations with them family and/or neighbors. $13 \%$ of the respondents said their community does not have this service and $28 \%$ of them said they do not know if their community has this service or not. This ratio is lower than that of life care services. So the solace and legal services have been carried out more efficiently and effectively with more publicity. People are more satisfied by this type of service than the life-care service.

\section{CONCLUSION}

From a practical point of view, the family pension is still dominating the ideology of the social supporting system for the elderly. And the children are still the main supporter of the elderly in finance, health care and spiritual solace.

1. Current Situations and Issues of Material Security

The most prominent problem in the material security services, few respondents received such pension service provided by the community, some of the elderly just heard about this service, while many people do not know of this service or their community does not have this service. And in contrast, almost all community social workers or persons incharge, said their communities have carried out many of such services for the elderly. This shows that the communities are not given enough publicity to this service or many potential clients are not aware of the existence of this service they need. On the other hand, it also tells us that the community home-stay pension service has been promoted by the government policies in Beijing but not much has been implemented.

During the survey, we also found that elderly from places outside of Beijing are not protected like a vacuum condition because of the difference in policies between different cities or urban and rural areas. Some of them were working outside of Beijing before retirement. Although they can receive their retirement pay through their bank account in time, they might not be able to get their new or festival allowances in time. Though they have medical insurance, they cannot go to their nominated hospital and claim the expenditures. They can pay for some minor ailments, but not a sudden and serious disease, in which case they will have to take care of the charges themselves. They are worried about this most. Furthermore, even if the communities in Beijing provide perfect life care and solace services, the elderly from places outside of Beijing cannot enjoy the service because their contacts have not been registered and the community workers are too busy to attend them. The demarcation and difference in the local welfare system and resources between urban and rural areas caused by the urban-rural dual structure has excluded the farmers from the social welfare and security system. Although the demarcation caused the urban-rural dual structure or similar isolation between cities in China has been existing for many years, the elderly from the places outside of Beijing shall also be taken care of in our community home-stay pension system, which is a peopleoriented highly efficient new system.

2. Current Situations and Problems of Life Care

Community home-stay pension services in Beijing are very limited and the services are normally very simple. Almost not a single community could provide all the types of the services for the elderly. And a lot of the elderly said that the service provided by the community are not required by them. The services required like chatting or shopping assistance are not provided.

In addition, we found during the conversations in the same survey, there is also difference in the low satisfaction of the community pension services: whoever received the service are holding a positive attitude towards the community work, however people with difficulties not been solved do not like the services provided by the community. So it does not suit everyone. Some respondents also mentioned that the workers in some communities are not well trained and professional, who might not be able to handle the household chores. This reminds us that the pension services in the community shall further improve the quality of their manpower, build sufficient reserves of professional people and create specialized community homestay pension service teams and volunteer teams, in order to achieve professionalization, and specialization of the whole team. At the same time, a standardized assessment and regulatory system shall be established, so that the elderly can build trust in the community service.

3. Current Situations and Problems of Life protection

The health level of the elderly population is lower than the others, and it deteriorate with the increase in age. The medical charges are one of the important expenditures for the elderly. Many of the respondent mentioned that they tried to 
avoid the best medicine to save money. And they could not afford the serious disease, though some minor ones will not cost a lot. Medical care in the chronic phase of the disease is particularly important for the elderly with chronic disease. Therefore the big expenses and great difficulty in medical treatment are still the general problems faced by the elderly. As per many respondents, the Beijing rule of $85 \%$ reimbursement over the amount of 1300 yuan is not good because the elderly are normally suffering from chronic or minor disease, costing around 1000 yuan a month. So they have to pay the entire charges. Meanwhile many specialized drugs are not within the scope of reimbursement, so the elderly cannot benefit much from the medical insurance.

The coverage of the community Health station for the elderly is not big enough. Most of them have only functions of prescription and dispensary, with little day-to-day diagnosis and follow-up for the elderly. And the fewer medical treatment services and low technical level refrain from the elderly to visit the health station. Moreover, due to limited funds and venue issues, the commuting time between some health stations and residential area are over half an hour. The elderly will choose the hospital nearby due to inconvenience and the concerns over the quality of the medical treatment, which is the main reason that the health station cannot replace the large hospital.

4. Current Situations and Problems of Solace

Currently there are some issues with the solace service provided by the community. There are not enough professional psychological counseling and legal advice service. The community could not answer or they have to refer it to the higher service agencies when receiving the inquiries of legal issues, which is tedious and inefficient. Situation permitting, each community should have at least one professional legal adviser and one psychological counselor. Otherwise, viable channels shall be provided to the elderly.

The elderly normally have a strong sense of loneliness. They hope to get the care from their children and the whole society. Currently there is very few one-to-one form of services such as accompanied meals or chat in the community. Most of the community will provide an activity center and organize collective entertainment activities. It is easy for the outgoing elderly to participate in singing and dancing activities and their mental status is getting better and better. However the unsocial elderly will not take the initiative to participate in the collective activities, staying lonely and not concerned by the others. The community shall provide solace service as per the different situation and different level of the elderly. Of course, the capability of the community is very limited. The key is to form multiple supply system led by the government, with the participating by the market and social organizations, which would be able to integrate the social resources and provide better services for the elderly.

\section{REFERENCES}

[1] Zhu Jige / Liu Xiaoqiang, the Progress and Implications of the Medical Security System in Foreign Countries, Foreign Medical, Health and Economics Volume, 2008, 25(3) pp. 97-102.

[2] Lao Yinqian / Cao Weigu / Li Yingdan, How the Medical Insurance System to Deal with the Impact of the ageing society, Union Expo: theoretical research,, 2011 (7) pp. 133-134.

[3] Cheng Haijun, The Plight and Countermeasures of China's Current Social Welfare for the Elderly, Journal of Capital Normal University (Social Sciences Edition), 2012,(1) pp. 123-129.

[4] Li Fengqin / Chen Quanxin, Exploring the Urban Community Homestay Pension Service Model - Example of Purchase of Service by Government of Gulou District, Nanjing City from the Heart-to-heart Service Center for the Elderly, Northwest Population Journal,2012,33(1) pp.46-50

[5] Ma Yuqin, Dong Gang, Xiong Linping, Teng Haiying, Zhao Xiaojun, Research on China's Medical Treatment Services for the Elderly: Based on the Demand of Medical Treatment Services, CHINESE HEALTH ECONOMICS, 2012,31(7), pp. 20-22.

[6] Cheng Shuling, Zang Xiaoying, Zhao Yue, The Investigation of the Current Status and Demand of the Nursing for Chronic Disease of the Elderly in China's Urban and Rural Area and the Analysis of the Factors, Chinese Journal of Practical Nursing, 2012,28(23), pp. 66-70.

[7] Wang Shibin, Shen Qunxi, The Main Psychological Problems of the Urban Elderly People and the Countermeasures - Cases of 878 Urban Elderly people in Guangdong, Chinese Journal of Gerontology, 2012, 32(2), pp. 361-363 